\title{
Penanaman Pohon Sebagai Upaya Meningkatkan Kesadaran Masyarakat Tentang Penghijauan Lingkungan
}

\author{
The Use Of Planting Trees As A Public Awareness Efforts To Improve On \\ Environmental Greening \\ Mukson $^{* 1}$, Ubaedillah ${ }^{2}$, Farhan Saefudin Wahid ${ }^{3}$ \\ ${ }^{1}$ Program Studi Manajemen, Fakultas Ekonomi dan Bisnis, Universitas Muhadi Setiabudi, Indonesia \\ ${ }^{2}$ Program Studi Pendidikan Bahasa dan Sastra Indonesia, Fakultas Keguruan dan Ilmu Pendidikan, \\ Universitas Muhadi Setiabudi, Indonesia \\ ${ }^{3}$ Program Studi Pendidikan Guru Sekolah Dasar, Fakultas Keguruan dan Ilmu Pendidikan, \\ Universitas Muhadi Setiabudi, Indonesia \\ e-mail: ${ }^{1}$ mukson.brebes@gmail.com, ${ }^{2}$ ubaedillah2@gmail.com, ${ }^{3}$ farhansaefudinwahid@gmail.com
}

\begin{abstract}
Abstrak
Penanaman pohon sebagai bentuk pelestarian lingkungan yang perlu dibudidayakan mulai dari lingkungan sekitar desa Pengabean melalui gerakan penanaman 600 pohon yang terdiri dari cemara laut, sirsak, jambu biji, mahoni, glodogan, gumitir, dan ketapang kencana, yang melibatkan masyarakat Desa Pengabean, Karang Taruna, dan Ranggon Ijo. Pergerakan 600 pohon ini diharapkan mampu menjadikan keran pertama kesadaran masyarakat untuk memiliki kepedulian terhadap lingkungan. Kegiatan ini tidak hanya bertujuan untuk mewujudkan Penghijauan di desa Pengabean serta membantu program dunia untuk mengurangi pemanasan global dan menyelamatkan tempat penampungan air.
\end{abstract}

Kata kunci-Penanaman Pohon, Kesadaran Masyarakat,Penghijauan Lingkungan

\begin{abstract}
Planting trees as a form of ove for the environment that needs to be cultivated starting from the environment around Pengabean village through the planting movement of 600 treesconsisting of sea cypress, soursop, guava, mahogany, glodogan, gumitir, and ketapang kencana, which involves the community of Pengabean village, Karang taruna, and Ranggon Ijo. The 600 tree movement is expected to be able to make the first tap of public awareness to have a concern for the environment. This activity is not only aimed at realizing go green in Pengabean village., but also helps world programs to reduce global warming and save water reservoirs
\end{abstract}

Keywords-planting trees, public awareness, enviromental greening.

\section{PENDAHULUAN}

Salah satu upaya penyelamatan lingkungan di Indonesia sebagai negara yang agraris melalui penghijauan.(Pratiwi, 2017). Desa Pengabean merupakan desa di wilayah utara dan termasuk dalam wilayah pantai utara (pantura), hal tersebut membuat desa Pengabean menjadi desa yang tergolong gersang dan bercuaca panas. Kurangnya pohon hijau di wilayah desa diakibatkan karena terus berlangsungnya pembangunan di desa tersebut. Mulai dari rumah hunian, ruko serta bangunan-bangunan yang lain. Perlu adanya kesadaran masyarakat dalam upaya melestarikan lingkungan agar pohon di wilayah tersebut tidak habis digantikan bangunanbangunan.

Beberapa kajian tentang kesadaran lingkungan telah dibahas sebelumnya termasuk dalam bidang ekonomi seperti penentuan produk ramah lingkungan yang menjadi tolak ukur produk tersebut. (Junaedi, 2015) Masalah yang mendasar dewasa ini adalah kurangnya kesadaran dan ilmu pengetahuan akan pentingnya kepedulian pada lngkungan. Seperti halnya sedaran 
membuang sampah yang menyebabkan banjir dan masalah lingkungan lainya. Hal ini menjadi tanggung jawab seluruh masayarakat dan tidak dibebankan pada individu. Upaya pengingkatan kepedulian terhadap lingkungan tersebut harus dibangun sejak dini.(Mohammad, 2018)

Permasalahan yang dihadapi secara sederhana dapat diuraikan: (1) Masih belum diterapkannnya program penghijauan secara berkala di lingkungan desa Pengabean Kecamatan Losari Kabupaten Brebes; (2) Masih rendahnya kesadaran warga desa untuk mencintai lingkungan terutama dalam hal penghijauan, dibuktikan dengan meningkatnya jumlah bangunan tanpa adanya penghijauan kembali.

Upaya Penanggulangan Degradasi serta menjaga lingkungan sebagai salah satu penataan wilayah ialah melalui sistem penghijauan atau penanaman pohon di wilayah tersebut. Memiliki lingkungan yang baik dan sehat adalah merupakan hak dan kewajiban bagi semua masyarakat di Indonesia, melalui penanaman pohon yang bertujuan untuk (1) Upaya peningkatan kwalitas lingkungan hidup, (2) penumbuhan kota dan daerah yang asri serta sehat dan (3) pembangunan daerah yang berorientasi pada kelestarian lingkungan.(Karim \& Makmur, 2019)

Solusi yang ditawarkan melalui pengabdian ini adalah: (1) Melibatkan mahasiswa Universitas Muhadi Setiabudi dan masyarakat desa Pengabean pada program penanaman 600 bibit pohon jenis jenis tanaman mahoni, cemara laut, jambu, ketapang kencana, gumitir, sirsak, dll. (2) Menumbuhkembangkan kesadaran masyarakat wilayah desa Pengabean akan pentingnya penghijauan terutama di lingkungan desa.

Target yang ingin dicapai melalui kegiatan pengabdian masyarakat ini adalah peningkatan sumber daya manusia yang sadar lingkungan tentang pentingnya program penghijauan lingkungan, yang diharapkan program ini bisa berkelanjutan melalui kesadaran menghijaukan lingkungan yang berawal dari lingkungan desa pengabean kemudian memberikan positif effect bagi lingkungan desa Pengabean pada khususnya dan Kabupaten Brebes pada umumnya.

\section{METODE PELAKSANAAN}

Persiapan penanaman pohon pelaksanaan kegiatan diawali dengan survey dan observasi lokasi pengabdian kepada masyarakat setempat untuk mengurus perizinan agar kegiatan berjalan dengan lancar dan mendapat dukungan dari masyarakat setempat. Melalui komunikasi yang intensif dengan melalui pendidikan karakter yang diberikan kepada masyarakat. (Toharudin, et al 2020) Tahap selanjutnya yaitu persiapan bibit pohon dengan jumlah 600 bibit pohon.

Pelaksanaan kegiatan pengabdian kepada masyarakat ini berlokasi di desa Pengabean, kecamatan Losari, kabupaten Brebes. Waktu pelaksanaan kegiatan ini pada tanggal 13 September 2020 selama kurang lebih 7 jam. Jumlah peserta yang mengikuti kegiatan ini kurang lebih 25 orang yang terdiri dari tokoh masyarakat desa, karang taruna, ranggon ijo dan mahasiswa Universitas Muhadi Setiabudi. Metode yang digunakan pada kegiatan pengabdian dimasyarakat ini antara lain (1) Serah Terima Bibit Pohon kepada masyarakat desa Pengabean ini diwakili oleh ketua Karang taruna, Ranggon Ijo dan direktur Universitas Muhadi Setiabudi. Penyerahan Bibit Pohon ini dilakukan pada jam 08.00 WIB, (2) pendampingan teknis penanaman. Penanaman 600 pohon dibagi menjadi 3 tempat yaitu, area sekitar kantor desa, area TPU, dan area kali ampel.

Pada kegiatan penanaman pohon menggunakan jenis bibit pohon berikut mahoni, cemara laut, jambu, ketapang kencana, gumitir, sirsak, dll. Pada pelaksanaan penanaman ini menyesuaikan dengan lokasi yaitu juga menyesuaikan dengan jenis pohon yang masyarakat minati. Pemilihan bibit didasarkan pada kecukupan adaptasi bibit tanaman tahunan sebagai berikut (Karim \& Makmur, 2019)

1. Perkembangan normal berdasarkan umur bibit pohon

2. Jenis tanaman sehat dan pertumbuhan normal

3. Tinggi bibit pohon antara $25 \mathrm{~s} . \mathrm{d} 35 \mathrm{~cm}$

4. Mempunyai akar yang kompak dan belum keluar dari polybag

$\overline{\text { Penanaman Pohon Sebagai Upaya Meningkatkan Kesadaran Masyarakat Tentang Penghijauan }}$ Lingkungan (Mukson, Ubaedillah, Farhan Saefudin Wahid) 
5. Kekuatan Polybag dalam pengangkutan, dan

6. Tanah pada polybag yang memenuhi syarat sebagai media tumbuh yang baik.

\section{HASIL DAN PEMBAHASAN}

Pada seluruh rangkaian pelaksanaan kegiatan pengabdian kepada masyarakat ini diketahui bahwa peserta sangat berpartisipasi dalam pelaksanaan kegiatan penanaman pohon. Wawancara menjadi dasar dalam pengambilan keputusan hasil pengabdian masyarakat ini (Ubaedillah, n.d.). Dari hasil wawancara dan tanggapan masyarakat $100 \%$ dapat diketahui bahwa penanaman pohon ini sangat bermanfaat, $90 \%$ beranggapan penanaman pohon ini ragu karena dengan keadaan cuaca yang panas, dan $70 \%$ menyatakan akan mencoba membudidayakan bibit tanaman dengan baik. Selain itu, masyarakat mendapatkan pengalaman, pengetahuan tentang keadaan lingkungam, sehingga masyarakat sendiri sadar dan memiliki rasa keperdulian terhadap lingkungan.

\section{Pelaksanaan Program Penanaman Pohon}

Adapun Tahapan pelaksanaan Program penamanan pohon yang telah berjalan dapat diuraikan seperti berikut ini:

\section{Sosialisasi Program}

Sosialisasi program penanaman pohon dilakukan melalui pertemuan informal dengan mengundang mahasiswa Universitas Muhadi Setiabudi. Melalui sosialisasi tersebut, disampaikan bahwa program terkait penghijauan dengan penanaman berbagai jenis tanaman, utamanya jenis bibit tanaman yang akan digunakan dalam kegiatan penaman, ditentukan sesuai dengan lokasi yang akan ditanami yaitu jenis tanaman mahoni, cemara laut, jambu, ketapang kencana, gumitir, sirsak, dll. Sosialisasi yang telah dilaksanakan ini merupakan bentuk penyadaran terhadap lingkungan, juga disampaikan secara teknis pelaksanaan kegiatan dan waktu pelaksanaan. Serta manfaat bagi masing-masing pohon yang ditanam bagi masyarakat desa Pengabean. Pentingnya manajemen komunikasi dibangun sebagai sarana kesadaran lingkungan (Wahyudin, 2017)

Reboisasi merupakan kegiatan menanam pada lahan kosong namun bukan merupakan hutan melainkan lahan milik pribadi atau milik masyarakat dan ditanam dengan jenis tanaman keras.Seperti sirsak, jambu, glodogan yang kita tanam di sekitar lahan masyarakat desa Pengabean agar bisa membuat tanah lebih kuat dan subur serta dapat mencegah berbagai bencana alam. Salah satu bibit pohon yang di utamakan adalah pohon mahoni. Mahoni adalah jenis tanaman yang dapat bertahan hidup ditanah gersang, manfaat pohon mahoni ini dapat dijadikan sebagai kesehatan yaitu dapat mengtasi rematik, sembelit, demam, meningkatkan nafsu makan, meredakan nyeri haid, dan masih banyak yang lainya. Tumbuhan tersebut tersebut digunkaan oleh masyarakat untuk diracik dan disajikan sebagai obat guna penyembuhan penyakit (Masrikhiyah, 2020)

\section{Penyerahan Bibit Pohon}

Dalam pelaksanaan kegiatan peserta khususnya masyarakat desa Pengabean yang terlihat sangat semangat dalam berpartisipasi penanaman pohon ini dilakukan mulai dari persiapan kegiatan diawali dengan persiapan keberangkatan tim yang dikoordinir oleh pihak penyelenggara dengan peserta. Persiapan meliputi pemaparan kembali, dan pengarahan panitia dilokasi nanti. Setelah seluruh peserta siap, peserta berkumpul terlebih dahulu di kantor desa untuk pengarahan penanaman, dilanjutkan dengan proses serah terima bibit pohon dari Universitas Muhadi Setiabudi kepada pihak desa Pengabean. 


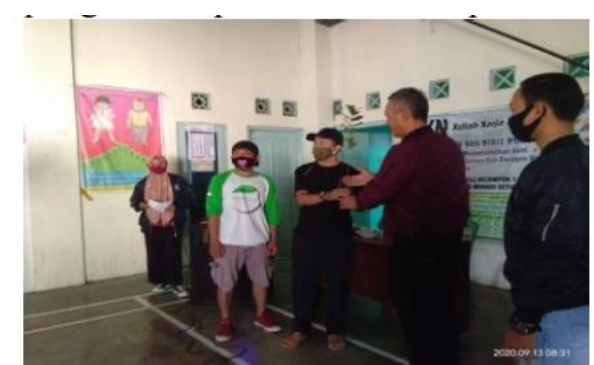

Gambar 1. Serah terima bibit pohon

Berdasarkan hasil pengamatan serah terima bibit pohon yang dilakukan sebelumnya para peserta sangat bersemangat untuk menanam pohon secara bersama-sama. Untuk melaksanakan kegiatan penanaman pohon tim pelaksana pengabdian terlebih dahulu melakukan penyerahan dan pengarahan. Penyerahan ini bertempat di Kantor Desa Pengabean, Kecamatan Losari, Kabupaten Brebes.

\section{Penanaman Bibit Pohon}

Pada Proses Penanaman terlebih dahulu dilakukan pembagian bibit pohon yang akan ditanam sesuai dengan wilayah dan jenis-jenis bibit pohon yang sudah di agendakan. Pada tahap ini evaluasi dilakukan oleh tim terkait pada wilayah-wilayah yang sudah menjadi titik penanaman pohon. Pembagian wilayah-wilayah tersebut antara lain: (1) Penanaman pohon di Sekitar jalan kantor desa, sebanyak 225 tanaman, dengan jenis tanaman antara lain; tanaman pohon glodogan, sirsak, jambu biji, cemara laut, dan gumitir. Jenis pohon ini yang akan ditanam di area sekitar jalan kantor desa karena bukan hanya mempunyai satu manfaat, melainkan ada manfaat lain yaitu dari aspek ekologis, aspek estetika, aspek keselamatan, dan aspek kenyamanan.

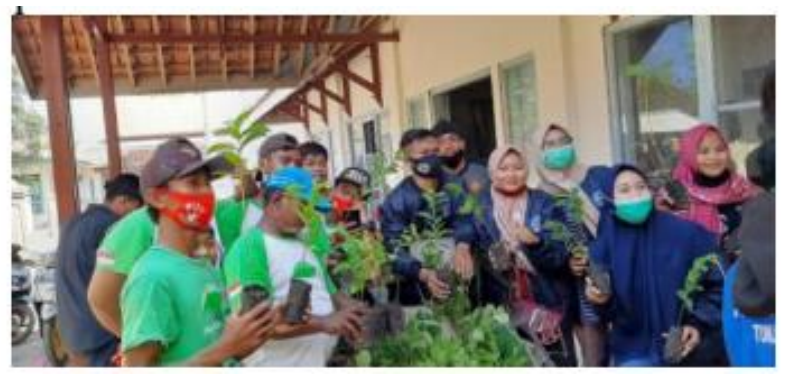

Gambar 2. Pembagian Bibit Pohon

Bagian dari tanaman yang menjadi pertimbangan pemanfaatannya adalah dari organ (batang, daun, buah, bunga dan prakaranya serta sifat perkembangannya). Bunga dan daun dapat menimbulkan kesan keindahan (estetika) dari beberapa bunga dan daun yang mengeluarkan aroma segar dan hijau, batang dan daun sebagai peneduh, pembatas penghalang angin dan penghalah cahaya matahari langsung. Sehingga area jalan kantor desa akan terlihat lebih segar dan hijau (2) Penanaman pohon di sekitar TPU desa Pengabean, sebanyak 75 tanaman dengan jenis tanaman antara lain: tanaman pohon cemara, sirsak, ketapang kencana dan jambu biji. Bibit pohon ini akan ditanam di area TPU, karena mempunyai banyak manfaat, salah satunya adalah menghilangkan pembuangan sampah di area TPU, sehingga di area TPU akan terlihat lebih bersih dan terhindar dari limbah sampah akibat pembungan sampah yang terus menerus (3) Penanaman pohon di sekitar sungai Ampel, sebanyak 300 tanaman dengan jenis tanaman, tanaman pohon mahoni, cemara laut, ketapang kencana, gumitir, dan flamboyan. 


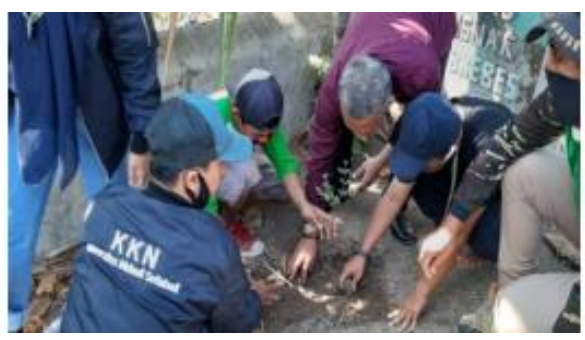

Gambar 2. Penanaman Bibit Pohon

Berdasarkan keadaan tempat dan tanah di sungai Ampel, maka Jenis bibit pohon ini yang akan ditanam di sekitar sungai Ampel, karena keadaan tanah sangat gersang, kering, dan tidak terawat sehingga dianggap perlu adanya penghijauan. Hal ini pula dapat menjadi awal baik bagi masyarakat Pengabean dalam upaya peningkatan ekonomi masyarakat melalui peningkatan sumber daya alam yang ada. (Utama, 2020) Penanaman pohon merupakan salah satu kegiatan penghijauan yang berdampak pada kegiatan ekonomi sosial masyarakat. (Pratiwi, 2017)

Proses penanaman dilakukan bersama-sama dengan Karang Taruna dan Ranggon Ijo secara bertahap. Pengelolaan penghijauan yang baik bergantung pada keterlibatan masyarakat itu sendiri (Arliman, 2015) Persiapan penanaman meliputi pengadaan bibit tanaman dan serta bahan dan alat yang dibutuhkan seperti sekop, patok, karung, linggis, cangkul, sabit, sapu lidi, dan yang lainnya. Penanaman dimulai dari jalan menuju kantor desa, dilanjut di sekitar TPU dan di sekitar sungai Ampel desa Pengabean. Perawatan bibit pohon, bibit pohon merupakan cara penanaman yang cukup menguras tenaga dan waktu, selain penanaman sudah ditanam, bibit yang sudah ditanam perlu adanya tinjauan dan perawatan seperti menyiram bibit tanaman yang sudah di tanam dengan air, sehingga tanaman apat tumbuh dengan baik. Untuk membuat bibit pohon bertumbuh dengan baik terutama perlu adanya penggunaan pupuk, karena pupuk berfungsi sebagai sumber zat hara untuk mencukupi kebutuhan nutrisi tanaman dan memperbaiki struktur tanah. Seperti pada bibit pohon jambu dan sirsak yang membutuhkan nutrisi, sehingga bibit pohon yang sudah ditanam akan tumbuh subur dan lebih ternutrisi.

\section{KESIMPULAN}

Simpulan dari pelaksanaan pengabdian program penanaman pohon adalah: (1) Stakeholder kampus dalam hal ini mahasiswa dan dosen Universitas Muhadi Setiabudi bekerja sama dengan pihak pemerintahan, karang taruna dan warga desa Pengabean terlibat langsung dalam program melalui penanaman tanaman pohon glodogan, sirsak, jambu biji, cemara laut, dan gumitir; (2) Program penanaman pohon telah terlaksana dengan baik yaitu penanaman lebih dari 600 bibit pohon tanaman pohon glodogan, sirsak, jambu biji, cemara laut, dan gumitir pada area kantor desa Pengabean dan di sekitar TPU dan di sekitar sungai Ampel desa Pengabean.

Saran yang dapat diberikan adalah pembinaan dan pengelolaan Penanaman pohon secara berkelanjutan sebagai wujud kesadaran dan kecintaan terhadap lingkungan dengan bekerja sama dengan pemerintah daerah setempat.

\section{UCAPAN TERIMAKASIH}

Ucapan terima kasih diucapkan kepada pihak yang telah mendukung pengabdian ini;

1. Kepala Desa Pengabean, telah memberikan ijin pelaksanaan kegiatan,

2. Warga masyarakat desa Pengabean, yang telah antusias dalam membantu kelancaran pelaksanaan kegiatan,

3. Karang Taruna dan Ranggon Ijo desa Pengabean atas keikutsertaannya,

4. Lembaga Pembelajaran, Penelitian, dan Pengabdian Masyarakat (LP3M) Universitas Muhadi Setiabudi yang telah mengijinkan kegiatan 


\section{DAFTAR PUSTAKA}

Arliman, L. (2015). Penegakan Hukum dan Kesadaran Masyarakat. Deepublish. depublish.

Junaedi, M. F. S. (2015). Pengaruh Kesadaran Lingkungan Pada Niat Beli Produk Hijau : Studi Perilaku Konsumen Berwawasan Lingkungan. Benefit, 9(2), 189-201.

Karim, I., \& Makmur, M. (2019). Program Green Campus melalui Penanaman Pohon Ketapang Kencana (Termenelia mantily) dan Ki Hujan (Samanea saman) dalam Upaya Mengurangi Global Warming. CARADDE: Jurnal Pengabdian Kepada Masyarakat, 2(1). https://doi.org/10.31960/caradde.v2i1.103

Masrikhiyah, R. et al. (2020). Peningkatan Pengetahuan Mengenai Manfaat Pangan Probiotik Dan Prebiotik Bagi Kesehatan Rifatul. JAMU : Jurnal Abdi Masyarakat UMUS, 1(1).

Moh., T. et al. (2020). Pemberdayaan Anak Usia Sekolah Dalam Menumbuhkan Nilai Karakter Melalui Strategi Pembiasaan Di Ppsa Tegal. JAMU: Jurnal Abdi Masyarakat UMUS, $1(1)$.

Mohammad, I. (2018). Project artikel pak arie. peduli lingkungan. December, 0-9.

Pratiwi, D. A. (2017). Pemberdayaan Masyarakat Rw 12 Dalam Kegiatan Penghijauan Lingkungan Di Kavling Mandiri Kelurahan Sei Pelunggut. Minda Baharu, 1(1), 25-32. https://doi.org/10.33373/jmb.v1i1.1170

Ubaedillah, U. (n.d.). Pelatihan Wawancara Kerja Dalam Bahasa Inggris Bagi Siswa Smk Menggunakan Metode Demonstrasi. Brebes) Dr. Moh. Toharudin, M.Pd, 1(01).

Utama, I. M. P. (2020). Praktik Pelestarian Lingkungan Melalui Kegiatan Penanaman Pohon di Kawasan Pesisir Pantai Mapak Mataram. Jurnal Hasil Pengabdian \& Pemberdayaan Kepada Masyarakat, 1(1), 22-27.

Wahyudin, U. (2017). Strategi Komunikasi Lingkungan Dalam Membangun. Jurnal Common, $1(2), 1$. 